\title{
НЕКОТОРЫЕ АСПЕКТЫ РАЗВИТИЯ ЧЕЛОВЕЧЕСКОГО КАПИТАЛА В ИННОВАЦИОННОЙ ЭКОНОМИКЕ
}

\author{
(c) 2021 Гайзатуллин Рамиль Ринатович \\ кандидат наук \\ Казанский (Приволжский) федеральный университет, Россия, Казань \\ E-mail: ramil.gayzatullin@tatar.ru \\ (C) 2021 Нестерова Олеся Александровна \\ аспирант \\ Казанский (Приволжский) федеральный университет, Россия, Казань \\ E-mail: lesya1609@mail.ru
}

В данной работе приведены материалы по развитию инновационной экономики через призму развития человеческого капитала на основе стимулирования и создания предпосылок для формирования созидающих способностей личности. Отмечено, что современная информационная глобализация, рассматриваемая как эпоха инновационного общественного развития, приоритетную роль в которой занимает повсеместное распространение информационных технологий, предъявляет все более веские требования к осмыслению роли человека в экономике нового типа. Представлено, что модернизация современной экономики, как показывают многочисленные исследования и опыт развитых стран, зависит от целого ряда предпосылок, в частности от способностей личности созидать, инновировать, а также особо выделены возрастающая роль знаний, создание, распространение информации и развитие технологий, т.к. именно информационно-технологический взрыв, породил формирование новой личности, с новыми желаниями, ценностями и новаторскими установками.

Ключевые слова: человеческий капитал, инноватор, инновационный человек, экономический рост, технологическое предпринимательство, интеллект.

Основные идеи о формировании человеческого капитала и его компонентах были обозначены еще А. Смитом, но полное оформление и развитие они получили во второй половине ХХв. в классических работах Т.Шульца и Г.Беккера, которые рассматривают расходы индивида на приобретение знаний и навыков как инвестиции, прибыль от которых реализуется на протяжении трудовой жизни индивида, что, несомненно, оказывает мультипликационное воздействие на накопление всего общественного богатства*

На основании систематизации основных подходов к содержанию человеческого капитала, представленных в экономической науке (таблица 1) можно сделать вывод о том, что в экономической теории категория «человеческий капитал» трактуется по-разному; при этом представители практически всех подходов связывают человеческий капитал не только с качеством жизни граждан, но и рассматривают его как основу стимулирования инновационной деятельности.

В целом, человеческий капитал, как и другие формы капитала, обладает своей стоимостью и может быть эффективно использован в личных или общественных целях (продан на рынке труда, использован в предпринимательской деятельности и т.д.). Отличительной особенностью является то, что человеческий капитал неотделим от носителя и при многократном использовании и продаже своего «личного капитала» не лишается приобретенных знаний, навыков и умения.

Человеческий капитал характеризуется продолжительностью накопления индивидуального капитала и занимает значительную часть жизни человека. В среднем накопление составляет порядка 18-25 лет и требует существенных материальных затрат, зависит от личной способности к саморазвитию и активности каждого индивидуума.

\footnotetext{
* Беккер С.Гэри. Человеческое поведение: экономический подход. Избранные труды по экономической теории / Пер. с англ. М.: ГУ-ВШЭ, 2003.-672 с.
} 
Таблица 1. Основные подходы к пониманию сущности человеческого капитала

\begin{tabular}{|c|c|c|}
\hline $\begin{array}{c}\text { Интерпретация сущно- } \\
\text { сти «человеческий } \\
\text { капитал» }\end{array}$ & Особенности восприятия (основные постулаты) & Авторы \\
\hline $\begin{array}{l}\text { Определяется как } \\
\text { запас и совокупность } \\
\text { знаний, навыков, спо- } \\
\text { собностей, здоровья и } \\
\text { мотивации }\end{array}$ & $\begin{array}{l}\text { Исследователи акцентируют внимание на таких составляющих } \\
\text { как образование, квалификация, жизненный и трудовой опыт и } \\
\text { др., что позволяет сформировать представление о накопленном } \\
\text { потенциале личности, а также его реализации. Отличительны- } \\
\text { ми чертами в восприятии является акцент на использовании } \\
\text { человеком способностей и навыков. В одном случае это для } \\
\text { индивидуальных целей, в другом - на реализации общественных } \\
\text { интересов }\end{array}$ & $\begin{array}{l}\text { Дж.С. Уолш, } \\
\text { Л. Тороу, } \\
\text { У.Боуэн, } \\
\text { В. Костюк и др. }\end{array}$ \\
\hline $\begin{array}{l}\text { Рассматривается как } \\
\text { запас способностей, } \\
\text { знаний и других харак- } \\
\text { теристик, позволяю- } \\
\text { щих получать высокий } \\
\text { доход в будущем. }\end{array}$ & $\begin{array}{l}\text { Содержат как характеристики накопленного потенциала лично- } \\
\text { сти, так и характеристики экономической эффективности (на ин- } \\
\text { дивидуальном уровне - доходы от реализации способностей и } \\
\text { навыков, на уровне предприятия - получение конкурентных пре- } \\
\text { имуществ, увеличение рентабельности выпускаемой продукции. } \\
\text { Капиталом является все то, что представляет собой источник } \\
\text { будущих удовлетворений, заработков, любой актив - физиче- } \\
\text { ский или человеческий, обладающий способностью генерировать } \\
\text { поток будущих доходов (Т.У.Шульц). }\end{array}$ & $\begin{array}{l}\text { Т. Шульц, } \\
\text { Ф. Махлуп, } \\
\text { И. Фишер и др. }\end{array}$ \\
\hline $\begin{array}{l}\text { Характеризуется как } \\
\text { сформированный в } \\
\text { результате инвестиций } \\
\text { запас способностей, } \\
\text { знаний и других ха- } \\
\text { рактеристик, позво- } \\
\text { ляющий получать } \\
\text { более высокий доход в } \\
\text { будущем }\end{array}$ & $\begin{array}{l}\text { Сформированный в результате инвестиций накопленный запас } \\
\text { знаний, здоровья, мотивации, способностей, которые целесо- } \\
\text { образно используются в той или иной сфере общественного } \\
\text { производства, содействуют росту производительности труда и } \\
\text { тем самым влияют на рост доходов этого человека (С.А.Дятлов). } \\
\text { Человеческий капитал - это экономическая категория, представ- } \\
\text { ляющая совокупность содержательных способностей, личных } \\
\text { качеств, накапливаемых за счет инвестиций, используемых в } \\
\text { национальном хозяйстве в течение определенного периода вре- } \\
\text { мени с целью получения доходов в будущем (Е.Д.Цыренова). }\end{array}$ & $\begin{array}{l}\text { С.А. Дятлов, } \\
\text { Е.Д.Цыренова, } \\
\text { Р.И.Капе- } \\
\text { люшников, } \\
\text { В.Т.Смирнов, } \\
\text { И.В.Скоблякова, } \\
\text { И.Т. Корогодин, } \\
\text { А.Н.Добрынин, }\end{array}$ \\
\hline $\begin{array}{l}\text { Выделяется как } \\
\text { всеобще-конкретная } \\
\text { форма человеческой } \\
\text { жизнедеятельности }\end{array}$ & $\begin{array}{l}\text { Человеческий капитал - всеобще-конкретная форма человече- } \\
\text { ской жизнедеятельности, ассимилирующая предшествующую } \\
\text { форму производительную и потребительную, адекватные эпохам } \\
\text { производящего и присваивающего хозяйства и осуществляющу- } \\
\text { юся как итог исторического движения общества к современному } \\
\text { состоянию (М. М. Критский). Человеческий капитал - основанное } \\
\text { на экономии времени обогащение жизнедеятельности, которое } \\
\text { является основным отношением современной инновационной } \\
\text { системы (Л.Г Симкина). }\end{array}$ & $\begin{array}{l}\text { М.М. Критский, } \\
\text { Л.Г. Симкина. }\end{array}$ \\
\hline
\end{tabular}

\section{Таблица 2. Система элементов и свойств человеческого капитала, оказывающих влияние} на формирование созидающего человека-инноватора

\begin{tabular}{|l|l|}
\hline $\begin{array}{c}\text { Элементы и свойства человече- } \\
\text { ского капитала, оказывающие } \\
\text { влияние на формирование } \\
\text { инновационого человека }\end{array}$ & $\begin{array}{l}\text { Совокупность знаний, квалификации, профессиональных навыков и уме- } \\
\text { ния, которые при эффективном использовании увеличивают производи- } \\
\text { тельность и генерируют потоки доходов }\end{array}$ \\
\hline Образование & $\begin{array}{l}\text { Совокупность таких качеств как физическая сила, выносливость, работо- } \\
\text { способность и иммунитет к болезням, которые продлевают период актив- } \\
\text { ной трудовой деятельности человека. }\end{array}$ \\
\hline $\begin{array}{l}\text { Социально-экономические } \\
\text { условия }\end{array}$ & $\begin{array}{l}\text { общественное благо, создаваемое свободным и рациональным индивидом } \\
\text { для достижения собственных выгод. }\end{array}$ \\
\hline Интеллект & $\begin{array}{l}\text { Перечень интеллектуальной собственности и формы закрепления автор- } \\
\text { ских прав (патент, авторское свидетельство, специальные документы). }\end{array}$ \\
\hline Мобильность & $\begin{array}{l}\text { Способность к быстрой адаптации в быстро меняющейся обстановке, уме- } \\
\text { ние находить нужные формы деятельности и эффективно использовать } \\
\text { информацию об экономической деятельности отраслей. }\end{array}$ \\
\hline
\end{tabular}


Человеческий капитал во многом нужно рассматривать с позиции инвестирования в совокупность созидательных способностей, а именно - в знания, умения и навыки, необходимые для поддержания и увеличения капитала, обеспечивающие, соответственно, интенсификацию процессов формирования и развития инновационных личностей.

Исходя из данных таблицы 2, классифицируем потенциальные источники экономической эффективности для человеческого капитала. Безусловно, в экономической теории имеются и другие подходы к систематизации элементов человеческого капитала, но, они лишь в той или иной мере дополняют предложенную нами структуру и не имеют критичного значения для последующего анализа диссертационной работы.

Рассмотрим выделенные элементы и свойства человеческого капитала контексте их влияния на процесс формирования и развития инновационного человека.

Капитал образования. Качество образования и профессиональный уровень специалиста подразумевает тщательное структурирование и управление своей деятельностью, которая во многом зависит от умений самостоятельно работать и саморазвиваться. Важными аспектами для человека являются такие умения, как - самостоятельно получать и анализировать необходимую информацию, выделять проблемы и находить способ их рационального решения, эффективно применять новоприобретенные знания.

Здоровье. Показатели уровня здоровья человека включают в структуру человеческого капитала многие исследователи, т.к. неудовлетворительное состояние здоровья снижает производительность труда и физически слабые, больные работники не могут в полной мере реализовать свой человеческий капитал.

Социально-экономические условия. Условия в которых находится человек, напрямую влияют на скорость принятия решений относительно материальной составляющей его жизнь. В данном контексте под социально-экономическими условиями мы будем понимать социальный капитал, который несмотря на разность точек зрения ученых (Дж.Коулманом. П.Бурдье), призвана быть, по мнению автора, как групповым, так и личностным ресурсом социальноэкономического блага.
Интеллект представляет собой элемент человеческого капитала, оказывающий непосредственное влияние на формирование инновационных личностей. Необходимо отметить, что интеллектуальный капитал общества формируется не только под влиянием системы образования, но и под воздействием ряда социальноэкономических институтов, таких, например, как институт публичных и бесплатных библиотек, институт свободных сетевых коммуникаций.

Мобильность представляет собой одно из свойств человеческого капитала и, вместе с тем, условий повышения эффективности процессов формирования и развития инновационных личностей. Так, мобильность подразумевает наличие возможности перемещения как внутри страны, так и по всему миру с целью совершенствования полученных знаний, обмена опытом, навыками, компетенциями. Мобильность является необходимым условием формирования современной экономики знаний, в условиях которой наиболее благоприятно развивается инновационный человек.

Человек-инноватор реализует ряд функций, основными из которых являются креативность, новаторство, жизнестойкость, стремление к непррывному образованию. Так, креативность представляет способность создавать новое, способность не только воспроизводить в своем сознании окружающий мир, но и понимать его нестандартно, видеть скрытые проблемы и возможности, что позволяет генерировать информацию и новые знания; принимать эффективные решения в условиях неопределенности, обучаться и изменяться.

Креативность является основным фактором эффективной социальной и экономической деятельности человека в современном обществе, характеризующимся непрерывным интеллектуально-инновационным развитием.

Новаторство выступает в качестве необходимого и важнейшего атрибута новой экономики. В современных условиях способность к выработке плодотворных бизнес-идей, предприимчивость, решительность, организаторский талант, владение коммерческими секретами являются объективно необходимыми активами инноватора, деятельность которого всегда связана с созданием новых комбинаций, с новым качеством работы и стремлением к самостоятельному делу.

Новаторство трактуется нами как способ- 
ность не только изобрести идею, но и включить ее в хозяйственный оборот. Новатор обладает совокупностью предпринимательских, организаторских способностей и качеств, которые отражают возможности людей к выработке плодотворных бизнес-идей и способность идти на риск. Качество и уровень данных способностей во многом определяются развитыми природными способностями конкретного человека, уровнем полученного образования, мотивацией к труду.

Таким образом, с приходом нового технологического уклада приоритетная роль отдается уже не отдельным человеческим качествам - умению выполнять определенные производственные операции, наличию профессиональных знаний и навыков в той или иной области, а рассматривается в целом, выделяя человеческую личность как обладателя совокупности знаний и способностей, главным образом - интеллектуальных и духовных. Со временем человеческая личность стала важнее организации, важнее сообщества людей. Соответственно, для модернизации экономики России и осуществления инновационной деятельности потребовался новый тип работника, не нуждающийся во внешней организации, способный к самоанализу и постановке эффективных целей, при этом избирая необходимую стратегию действий и оперативно решая поставленные задачи.

Как было ранее отмечено, человек нового времени предпочитает трудиться за меньшую заработную плату, если его деятельность на рабочем месте максимальным образом способствует личной самореализации, где нет необходимости выполнения рутинных операций и есть возможность приема самостоятельного решения, при реализации выделения большего времени на свою семью и участие в различных общественных организациях.

В интересах формирования инновационного человека, необходимо создавать новые механизмы, обеспечивающие усовершенствование базовых способностей лежащих в основе развития творческой личности. К ним относятся:

- способность к формированию нравственного и ответственного миропонимания и управления инновационными процессами;

- способность к разработке и реализации инновационных новшеств во всех сферах жизнедеятельности на основе нравственного и ответственного отношения к окружающей среде;
- способность к управлению собственным качеством жизни и здоровьем, путем формирования нравственных принципов и миропонимания.

При этом под нравственным миропониманием подразумевается такая система взглядов и принципов, которая определяет ответственное отношение человека к обществу, среде и новым разработкам и последствиям данных разработок. Нравственное миропонимание основано на накоплении и генерации знаний принятых человеком, которые являются фундаментом для позитивного изменения окружающего мира. Данные характеристики дают основание для трансформации именно нравственного человека в современном обществе, где процесс перехода обозначается от традиционного к инновационному.

Подводя итог рассмотрению взаимосвязи человеческого капитала и инновационного человека, как понятий экономических категорий, систематизируем направления их взаимного влияния (рис. 1).

Положительное влияние человеческого капитала на процесс формирования, развития и совершенствования инновационных личностей можно доказать и статистически. Проблема здесь заключается в том, что напрямую измерить количество инновационных личностей в экономике достаточно проблематично: очевидно, что далеко не все сотрудники НИИ, вузов или КБ предприятий являются инновационными личностями в соответствии с предложенным нами в п. 1.1 диссертационного исследования определением. Вместе с тем, например, и некоторые официальные безработные могут быть инновационными личностями и, при определенных дополнительных условиях, принести существенный положительный эффект для экономики государства.

Вместе с тем, в официальной статистике существуют наиболее общие относительные показатели интенсивности инновационной деятельности в экономике государства, которые свидетельствуют в том числе и об активности инновационных личностей, о характере их участия в экономических процессов. Наиболее значимыми из такого рода показателей являются: отношение затрат на исследования и инновационные разработки к ВВП; доля инновационной продукции в общем объеме промышленного производства. 


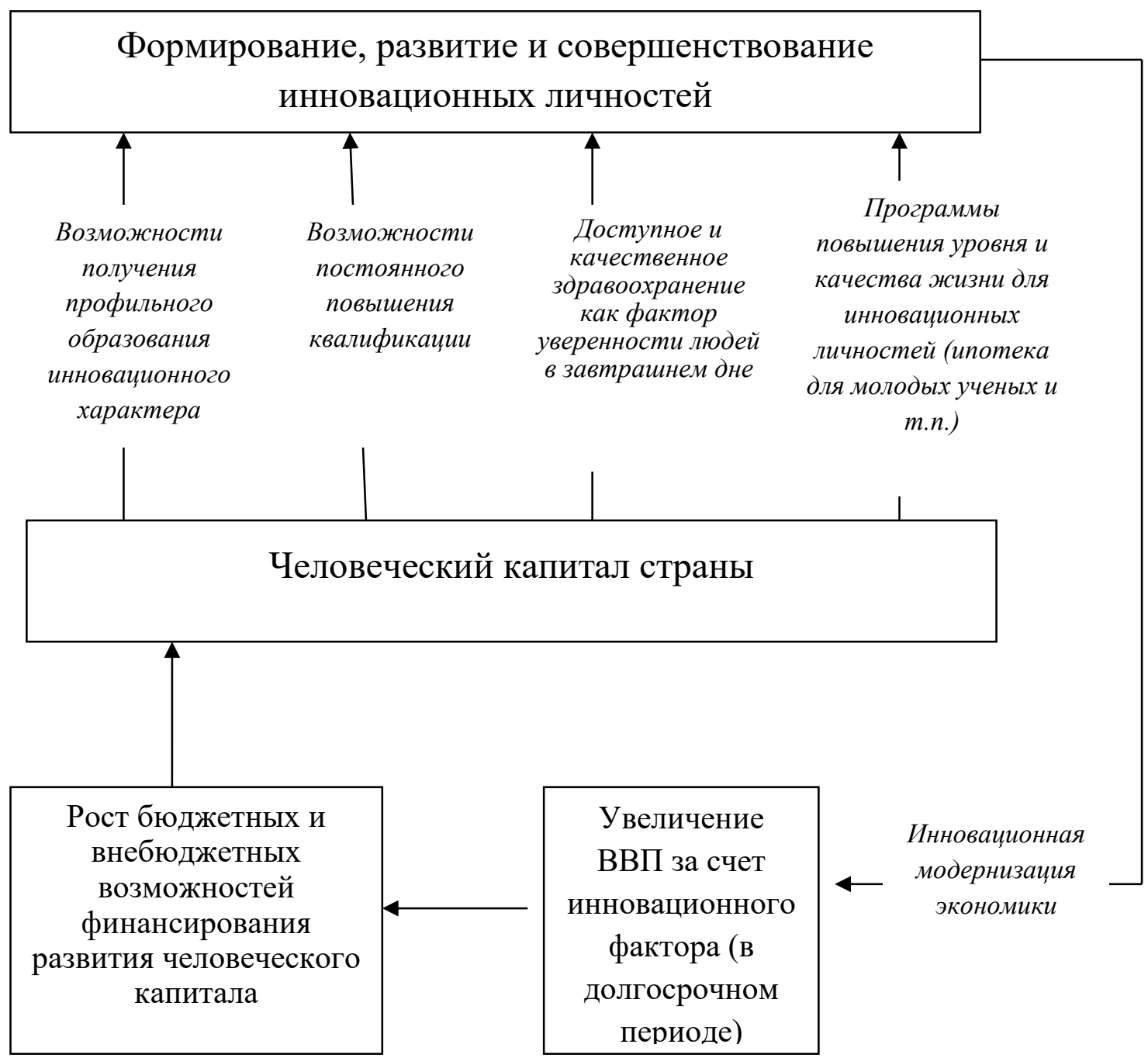

Puc. 1. Взаимосвязи человеческого капитала и формирования инновационных личностей

Действительно, чем выше доля инновационной продукции в общем объеме производства, тем, соответственно, более активной является деятельность инновационных личностей по разработке и внедрению принципиально новых или существенно усовершенствованных продуктов. Вместе с тем, если инновационные личности играют существенную роль в экономике государства, то они оказывают влияние и на увели- чение объемов финансирования исследований и инновационных разработок, финансируемых как за счет бюджетных, так и внебюджетных источников. Тем самым, представленные показатели интенсивности инновационного развития одновременно являются и индикаторами роли инновационных личностей в экономике государства.

\section{Библиографический список}

1. Беккер, Г. Человеческое поведение: экономический подход. Избранные труды по экономической теории / Г. Беккер - М.: ГУ ВШЭ, 2003.- 650 с.

2. Белянин, А. Даниэл Канеман и Вернон Смит: экономический анализ человеческого поведения / А. Белянии // Вопросы экономики.-2003.- № 4.- С.4-24.

3. Блауг, М. Методология экономической науки. / М. Блауг - М.: НП «Журнал Вопросы экономики», 2004.-416 c. 
4. Власов, Ф. Культурно-нравственный капитал (показатели, оценки и роль в экономике) / Ф. Власов // Человек и труд. - 2013. - № 9.- С.44-47

5. Добрынин, А. Человеческий капитал в транзитивной экономике: формирование, оценка, эффективность использования / А. Добрынин, С. Дятлов, Е. Цыренова.- СПб.: Наука, 1999.- 90 с.

6. Дорохов А.В. Инновационное поведение и социальное расслоение: проблема соотношения // Бизнесжурнал.-2013. - № 4.- С. 11-13.

7. Иноземцев, В. Современное постиндустриальное общество: природа, противоречия, перспективы: Уч. нос. / В. Иноземцев. -М.: Логос, 2000.-293 с.

8. Исламутдинов В.Ф., Шангараев Р.Г. К вопросу о концепции инновационного человека // Вопросы инновационной экономики. - 2011. - № 4.- С.3-12.

9. Сафиуллин, Л.Н. Предпринимательская деятельность на рынке услуг: сущность и особенности развития в экономике знаний / Л. Н. Сафиуллин, Д. В. Улесов. - Казань: Центр инновационных технологий, 2010. - 201 c.

10. Фахрутдинова Е. В. Диалектика потребностей человека// Экономические науки. 2009. № 57. С.43-47.

11. Фахрутдинова Е.В. Человеческий капитал в Республике Татарстан: динамика развития// Вопросы экономики и права. 2013. № 66. С.121-124.

12. Экономическая теория/Под ред. Добрынина А. И., Тарасевича Л. С.-Спб.: Питер, 2013. - 544 с.

13. Black C. The Dynamics of Modernization. A Study in Comparative History. N.Y.: Harper Colophon Books, 2008. P. 186-187.

14. Bailetti T. Technology Entrepreneurship: Overview, Definition, and Distinctive Aspects // Technology Innovation Management Review. 2012. Vol. 2. № 2. P. 5-12.

15. Kelly $R$. Creative Development: Transforming Education through Design Thinking, Innovation, and Invention.Canada, Brush, 2016.

16. Khan M.T., Kumar N. Technology Entrepreneurship Capability Development in Indian Automotive Industry // Advances in Interdisciplinary Engineering. 2019. P. 561-567.

17. Fuentelsaz L., Maicas J. P., Montero J. Entrepreneurs and innovation: The contingent role of institutional factors // International Small Business Journal: Researching Entrepreneurship. 2018. Vol. 36. Issue: 6. P. 686-711. 